\title{
ENTIRELY AQUEOUS SOLUTION-GEL ROUTE FOR THE PREPARATION OF ZIRCONIUM CARBIDE, HAFNIUM CARBIDE AND THEIR TERNARY CARBIDE POWDERS
}

\author{
CHUNLEI YAN, "RONGJUN LIU, CHANGRUI ZHANG, YINGBIN CAO \\ Science and Technology on Advanced Ceramic Fibers and Composites Laboratory, \\ National University of Defense Technology, Changsha 410073, China \\ "E-mail: rongjunliu@nudt.edu.cn
}

Submitted April 21, 2016; accepted June 10, 2016

\begin{abstract}
Keywords: Metal Carbide, Preceramic precursor, Aqueous route, Nanoparticle
An entirely aqueous solution-gel route has been developed for the synthesis of zirconium carbide, hafnium carbide and their ternary carbide powders. Zirconium oxychloride $\left(\mathrm{ZrOCl}_{2} \cdot 8 \mathrm{H}_{2} \mathrm{O}\right)$, malic acid (MA) and ethylene glycol (EG) were dissolved in water to form the aqueous zirconium carbide precursor. Afterwards, this aqueous precursor was gelled and transformed into zirconium carbide at a relatively low temperature $\left(1200^{\circ} \mathrm{C}\right)$ for achieving an intimate mixing of the intermediate products. Hafnium and the ternary carbide powders were also synthesized via the same aqueous route. All the zirconium, hafnium and ternary carbide powders exhibited a particle size of $\sim 100 \mathrm{~nm}$.
\end{abstract}

\section{INTRODUCTION}

Transition metal carbides are known for their high melting points, excellent high-temperature corrosion resistance, and weak damage sensitivity under irradiation. As a result, these carbides demonstrate applications in extreme environments of thermal protection systems, field emitters, coating of nuclear particle fuels [1-3]. Among these carbides, $\mathrm{ZrC}$ and $\mathrm{HfC}$ have been greatly studied for their high melting points and excellent corrosion resistance. However, HfC has limited applications due to its scarcity and high density [4-6], and the ternary carbides of zirconium and hafnium are expected to be a probable strategy to resolve this problem.

Despite a large number of papers about synthesis of metal carbides, a general environmentally benign and competitive synthetic method to simplify and scale up their production as fine particles is still looking for. Conventional solid-state synthesis of metal carbides always requires high temperatures and a long production period [7]. The sol-gel method shows apparent advantages over the conventional solid-state route, not only for achieving homogeneous mixing of the component on atomic scale, but also the ability to form fibers and thin films. However, one of the major problems concerning the conventional sol-gel process is the toxicity of the solvents and reagents normally used in the experiments. Other handicaps, for example, the hydrolysis sensitivity of the alkoxides used as starting reagents, add technological problems to the fabrication process [8-13]. Both ecological and technical aspects hamper the application of these processes in the industrial sector and necessitate the search for alternative processing routes for the preparation of carbide powders. An entirely aqueous synthetic route would solve the aforementioned problems, where water is used instead of organic solvents, promoting both environmental and technical benefits.

In this paper, we like to show an aqueous polymerized complex route, based on polyesterification between malic acid (MA)-metal complex and ethylene glycol (EG), to produce zirconium, hafnium and their ternary carbide powders at relatively low temperatures. The feasibility of this aqueous method to minimize the amount of toxic chemicals during solution processing is expected to be verified.

\section{EXPERIMENTAL}

A general procedure for the precursor preparation was depicted as follows. Firstly, the appropriate quantities of malic acid (MA) were dissolved in distilled water under stirring at room temperature to form clear solutions. Afterwards, the metal salt $\left(\mathrm{ZrOCl}_{2} \cdot 8 \mathrm{H}_{2} \mathrm{O}\right.$ or $\mathrm{HfOCl}_{2} \cdot 8 \mathrm{H}_{2} \mathrm{O}$ or both) was added. After the dissolution of metal salt, the ethylene glycol (EG) was added under stirring to form the metal carbide precursor. Before the main experiments, several trial and errors were conducted to optimize the molar ratio among the metal salt, MA, and EG. Based on these results, we set the $\mathrm{MA} / \mathrm{EG} /$ metal molar ratio to $1 / 1 / 1$. As far as the ternary 
carbide precursors were concerned, the metal source was comprised of zirconium and hafnium salts in the molar ratios $0.5 \mathrm{Hf}: 0.5 \mathrm{Zr}$ and $0.9 \mathrm{Hf}: 0.1 \mathrm{Zr}$ and the other preparing procedure was the same as the binary carbide. All precursor solutions were placed in alumina crucibles, and then under heat treatments at $150^{\circ} \mathrm{C}$ to form dried gels. The gels were then put into a graphite furnace which was heated in flowing argon (purity $99.999 \%$ ) to the desired temperatures at $7^{\circ} \mathrm{C} \cdot \mathrm{min}^{-1}$ and then in vacuum $(\sim 20 \mathrm{~Pa})$ at the final temperatures for $2 \mathrm{~h}$. Finally, black powders were obtained.

Fourier transform infrared spectra (FT-IR, Avatar 360 , Nicolet) were recorded between 4000 and $400 \mathrm{~cm}^{-1}$. The phase compositions were determined using X-ray diffractometry (XRD, D8 Diffractometer, Bruker) with $\mathrm{CuK}_{\alpha}$ radiation. The thermal behavior of the $\mathrm{ZrC}$ precursor was measured by differential scanning calorimetry and thermal gravimetric analysis (DSC-TG, Netzsch STA 449F3) in an argon atmosphere at a heating rate of $10^{\circ} \mathrm{C} \cdot \mathrm{min}^{-1}$. The particle size and morphology of powder samples were characterized using scanning electron microscope (S4800 Hitachi) and transmission electron microscopy (TEM, Tecnai F20). XPS measurements were performed with a Thermo Scientific ESCALAB 250Xi electron spectrometer using $\mathrm{AlK}_{\alpha} \mathrm{X}$-ray line $(1486.6 \mathrm{eV})$ with a resolution of $0.45 \mathrm{eV}$.

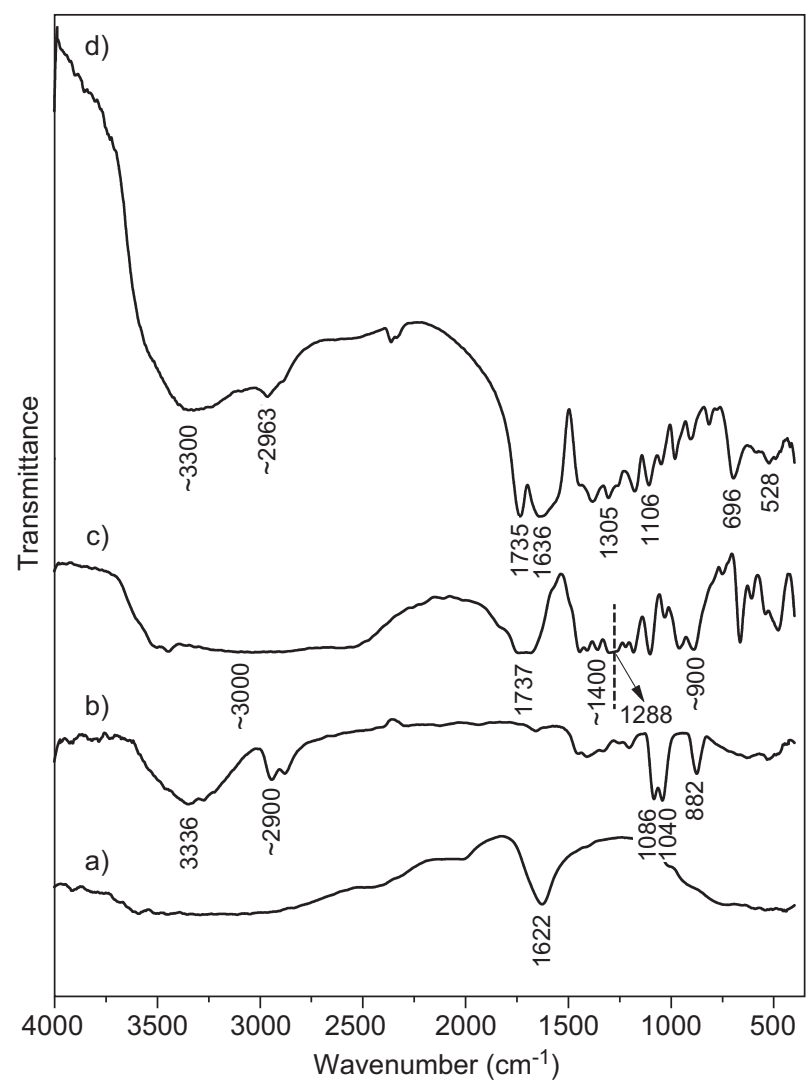

Figure 1. FT-IR spectra of: a) $\mathrm{ZrOCl}_{2} \cdot 8 \mathrm{H}_{2} \mathrm{O}$, b) ethylene glycol, c) malic acid, (d) $\mathrm{ZrC}$ precursor after heat treatment at $150^{\circ} \mathrm{C}$ for $8 \mathrm{~h}$.

\section{RESULTS AND DISCUSSION}

In our precursor preparation process, the universal and mainly nontoxic chemical reagents were used. In addition, It should be emphasized that the very important practical and environmentally beneficial aspects of this method are connected with the use of water as an economical and safe solvent and the easy handling technique (no dry and inert atmosphere is required). Figure 1 shows FT-IR spectra for chemical reagents and $\mathrm{ZrC}$ precursor. In the FT-IR curve of as-received $\mathrm{ZrOCl}_{2} \cdot 8 \mathrm{H}_{2} \mathrm{O}$, the band at $1622 \mathrm{~cm}^{-1}$ is assigned to the "scissor" bending mode of coordinated water. For ethylene glycol, the bands at 3336, 2900 $\mathrm{cm}^{-1}$ are attributed to the vibration of $\mathrm{O}-\mathrm{H}$ and $\mathrm{CH}_{2}$, besides, the doublets at $1086,1040 \mathrm{~cm}^{-1}$ are assigned to the vibration mode of $\mathrm{C}-\mathrm{O}$. As far as the malic acid is concerned, the stretching vibration of $\mathrm{O}-\mathrm{H}$ in carboxylate group shows a broad band at $\sim 3000 \mathrm{~cm}^{-1}$, and the bending mode of the same group exhibits two bands at $\sim 1400$ and $\sim 900 \mathrm{~cm}^{-1}$. Moreover, the stretching modes for $\mathrm{C}-\mathrm{O}$ and $\mathrm{C}=\mathrm{O}$ in carboxylate group show absorption bands at 1288 and $1737 \mathrm{~cm}^{-1}$, respectively. After the introduction of zirconium ion to form the $\mathrm{ZrC}$ precursor, its FT-IR spectrum presents significant differences (Figure 1d). The most striking result is that the IR absorption for $\mathrm{C}=\mathrm{O}$ groups gives rise to two bands at $1735,1636 \mathrm{~cm}^{-1}$, compared with the single band for the as-received malic acid. The former at $1735 \mathrm{~cm}^{-1}$ is close to $1737 \mathrm{~cm}^{-1}$, which suggests that free malic acid or carboxylate group without involving coordination still exists in the $\mathrm{ZrC}$ precursor. More importantly, the latter band at $1636 \mathrm{~cm}^{-1}$, shifting to lower wavenumber in comparison to the corresponding band of the free malic acid, indicates

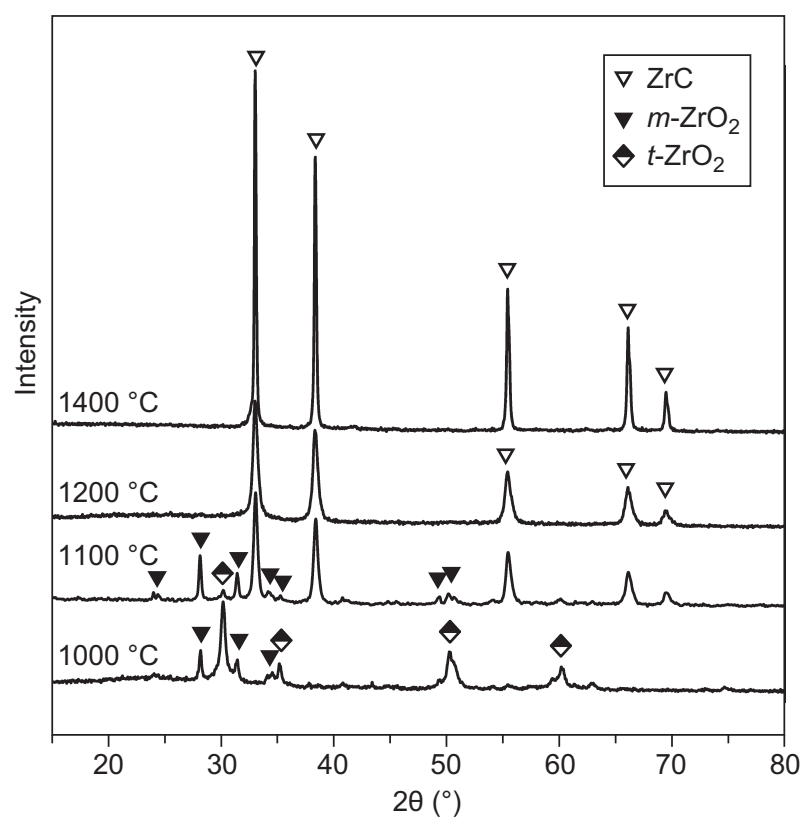

Figure 2. XRD patterns of $\mathrm{ZrC}$ precursor pyrolysed at varying temperatures. 
a change in the vibrational status of the malic anion upon coordination to the zirconium ion. Besides, the bands at 696 and $528 \mathrm{~cm}^{-1}$ assigned to the vibrations of $\mathrm{Zr}-\mathrm{O}$ further confirm the coordination of malic acid to zirconium ion $[14,15]$.

Figure 2 shows XRD patterns of $\mathrm{ZrC}$ precursor pyrolysed at varying temperatures. The XRD pattern of $1000^{\circ} \mathrm{C}$ indicates $\mathrm{t}-\mathrm{ZrO}_{2}$ and $\mathrm{m}-\mathrm{ZrO}_{2}$ exists in the pyrolysed products simultaneously, however, no diffraction peaks can be found for the pyrolysed carbon, indicating the amorphous state for this carbon. The $\mathrm{ZrC}$ phase appears as a major phase in the products obtained at $1100^{\circ} \mathrm{C}$. After heat treatments at $1200^{\circ} \mathrm{C}$, the precursor has completely transformed into $\mathrm{ZrC}$ without any $\mathrm{ZrO}_{2}$ phase, however, the diffraction peaks of $\mathrm{ZrC}$ are relatively broad, indicating poor crystalline state of the $\mathrm{ZrC}$ powders. In the following heat treatments of $1400^{\circ} \mathrm{C}$, the XRD pattern of final products shows sharp peaks; indicating that a well crystallized $\mathrm{ZrC}$ product has been obtained with the increase of pyrolysing temperature.

Since the vacuum environment is difficult to achieve in the DSC-TG testing, we obtain the DSC-TG curves of $\mathrm{ZrC}$ precursor in flowing argon atmosphere as shown

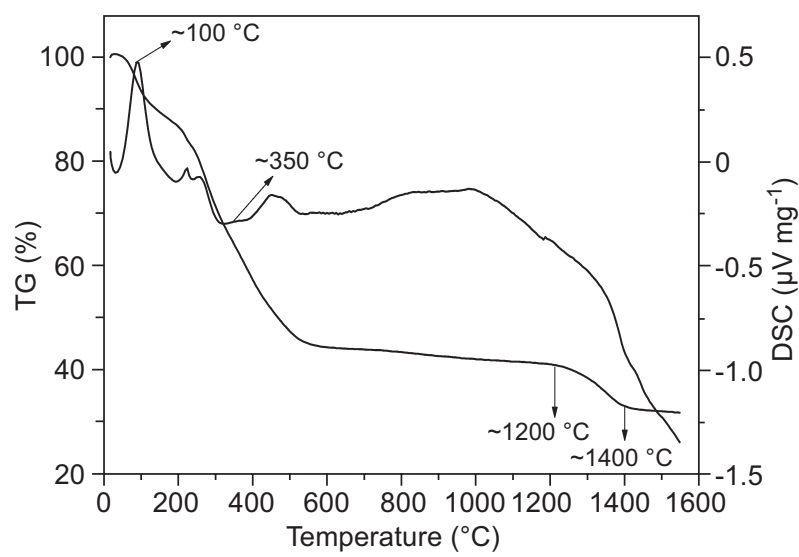

a) $\mathrm{ZrC}$ precursor

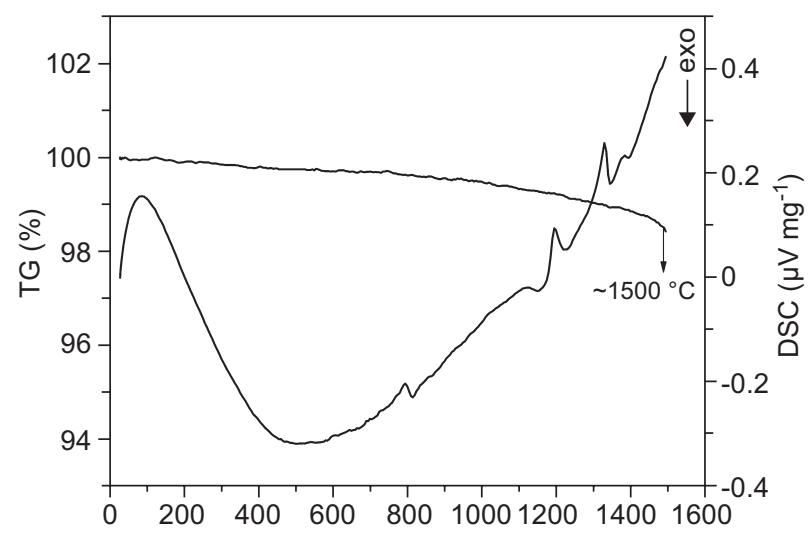

b) graphite and $\mathrm{ZrO}_{2}$ mixture

Figure 3. DSC-TG curves of: a) $\mathrm{ZrC}$ precursor and b) graphite and $\mathrm{ZrO}_{2}$ mixture. in Figure 3a. As a comparison, the traditional method to produce $\mathrm{ZrC}$ powders, i.e. graphite and $\mathrm{ZrO}_{2}$ by simple physical mixing, has also been carried out, and its DSC-TG curves are shown in Figure $3 \mathrm{~b}$. The TG curve of $\mathrm{ZrC}$ precursor (Figure 3a) shows three rapid weight loss regions in the whole pyrolysis process, i.e. $50-150^{\circ} \mathrm{C}$, $200-550^{\circ} \mathrm{C}$ and $1200-1400^{\circ} \mathrm{C}$. The weight loss in the region of $50-150^{\circ} \mathrm{C}$ is due to the evaporation of water, including physisorbed water and the water originating from esterification reaction, which results in an endothermic peak at $\sim 100^{\circ} \mathrm{C}$ in the DSC curve. The weight loss at $200-550^{\circ} \mathrm{C}$ is observed as the polymerization, and finally the carbonization are proceeding in this temperature region, which corresponds to an exothermic peak at $\sim 350^{\circ} \mathrm{C}$. The high temperature weight loss from 1200 to $1400^{\circ} \mathrm{C}$ is believed to be attributed to the carbothermal reduction reactions. The carbothermal reduction for $\mathrm{ZrC}$ precursor starts at $\sim 1200^{\circ} \mathrm{C}, 300^{\circ} \mathrm{C}$ lower than graphite and $\mathrm{ZrO}_{2}$ mixture (Figure 3b), confirming the intimate mixing with shorter diffusion distance in the precursor system. Meanwhile, note the results from $\mathrm{XRD}$ patterns of $\mathrm{ZrC}$ precursor at varying temperatures, the carbothermal reduction starts and ends at lower temperatures under vacuum condition than in flowing argon. This can be explained by equilibrium

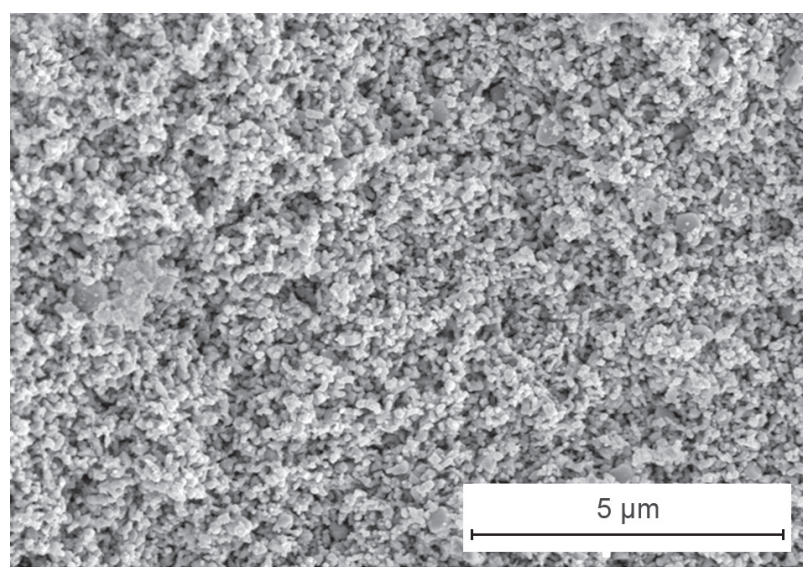

a)

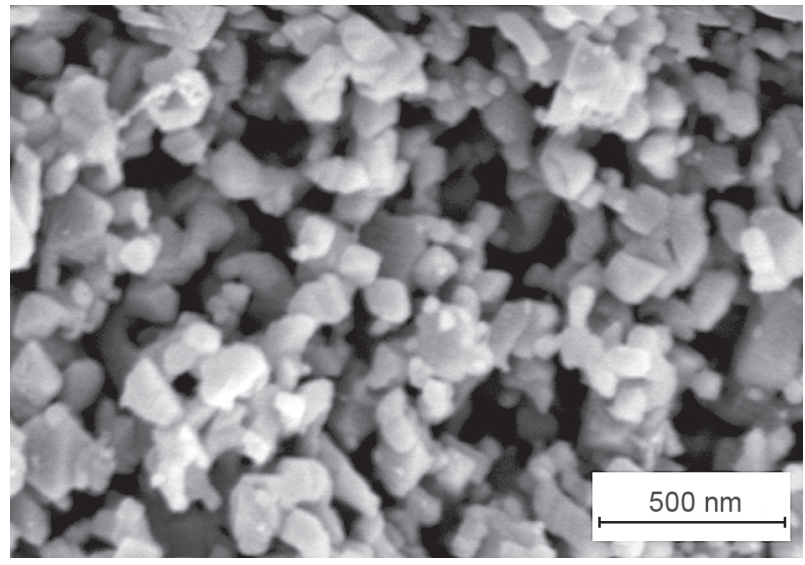

b)

Figure 4. SEM images of $\mathrm{ZrC}$ powders obtained at $1400^{\circ} \mathrm{C}$. 
theory. Although the $\mathrm{CO}$ par-tial pressure is below the equilibrium pressure in both cases, in flowing argon atmosphere the formed $\mathrm{CO}$ is around the local reaction site and migrates slowly, while under vacuum condition, once the new $\mathrm{CO}$ forms, it will be pumped out immediately to make the reaction equilibrium shift to the direction of carbide formation continuously.

Morphologies of $\mathrm{ZrC}$ powders obtained at $1400^{\circ} \mathrm{C}$ are shown in Figure 4. Especially, SEM is able to judge the homogeneity of the samples on a large scale. In our case, SEM image shown in Figure 4a confirms the homogeneity of the final $\mathrm{ZrC}$ powders, besides; many pores intercross among these ceramic powders for the consumption of the organic components. The $\mathrm{ZrC}$ powders magnified in Figure 4b consist of small welldefined crystal particles with narrow size distribution. It can be roughly estimated that the particle size of $\mathrm{ZrC}$ powders lies in the range of 50-200 nm.

Hafnium and the ternary carbide powders were also synthesized by the same aqueous solution-gel route. Zirconium oxychloride was employed together with hafnium oxychloride in the molar ratios of $0.5 \mathrm{Hf}: 0.5 \mathrm{Zr}$ and $0.9 \mathrm{Hf}: 0.1 \mathrm{Zr}$ to prepare the ternary carbide powders. The XRD patterns in Figure 5a show only lines due to carbide phase and provide no evidence of any oxide phase, besides, these ternary carbide powders exhibit a single-phase of NaCl-type. The magnified image of the dashed zones of Figure 5a shows the peaks located at $2 \theta=31.5-41$ degrees in detail. It can be observed that these peaks locate at lower degrees for pure $\mathrm{ZrC}$, and then shift to higher degrees with the increase of Hf content, finally show the highest degree for the pure HfC. Despite the similarity in radius of the metal ions, the diffraction peaks for the ternary systems do fall between those pure $\mathrm{ZrC}$ and $\mathrm{HfC}$, indicating that a solid-solution ternary product has been obtained. The SEM images of the pure $\mathrm{HfC}$ and ternary $\mathrm{Zr}_{0.5} \mathrm{Hf}_{0.5} \mathrm{C}$ products (Figure $5 \mathrm{c}$, d) show well-defined crystal particles with narrow size distribution. Both pure $\mathrm{HfC}$ and ternary $\mathrm{Zr}_{0.5} \mathrm{Hf}_{0.5} \mathrm{C}$ have a particle size of $\sim 100 \mathrm{~nm}$. XPS survey scan of $\mathrm{Hf}_{0.5} \mathrm{Zr}_{0.5} \mathrm{C}$ powders shown in Figure 6 shows that the product only consists of $\mathrm{Hf}, \mathrm{Zr}, \mathrm{C}$ and $\mathrm{O}$ elements, which

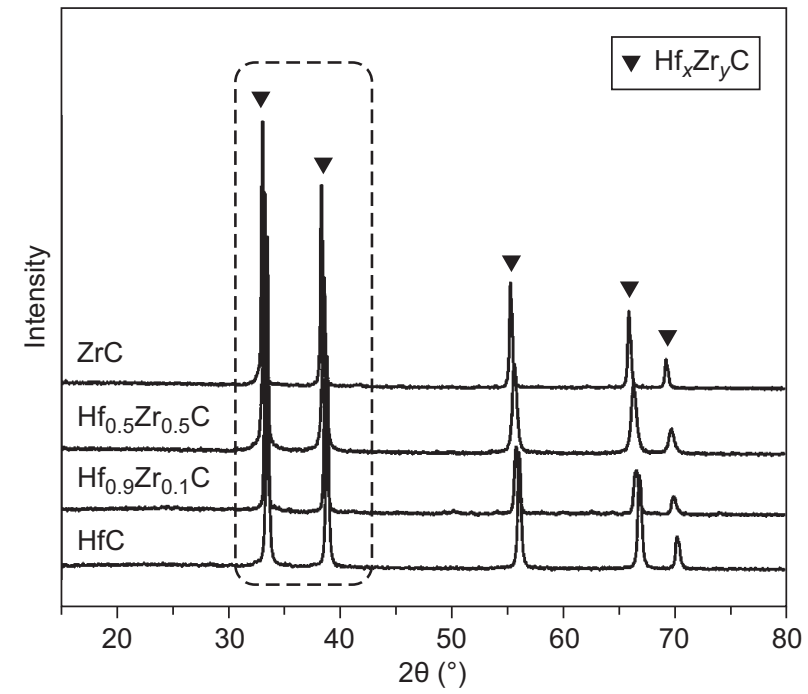

a)

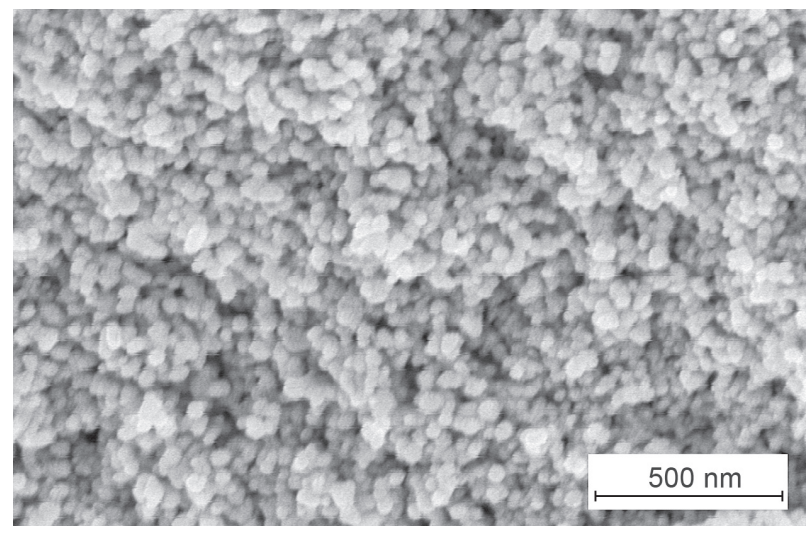

c)

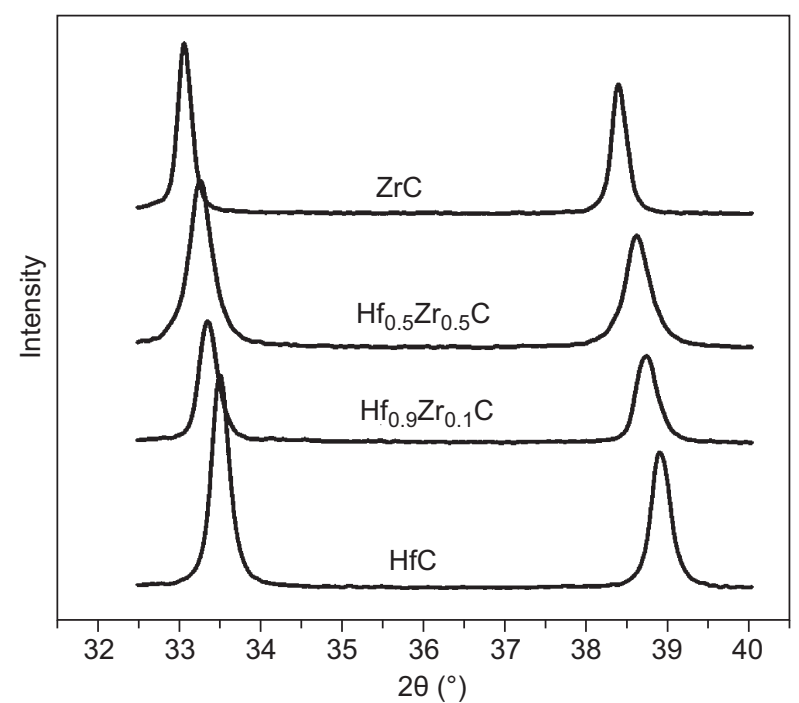

b)

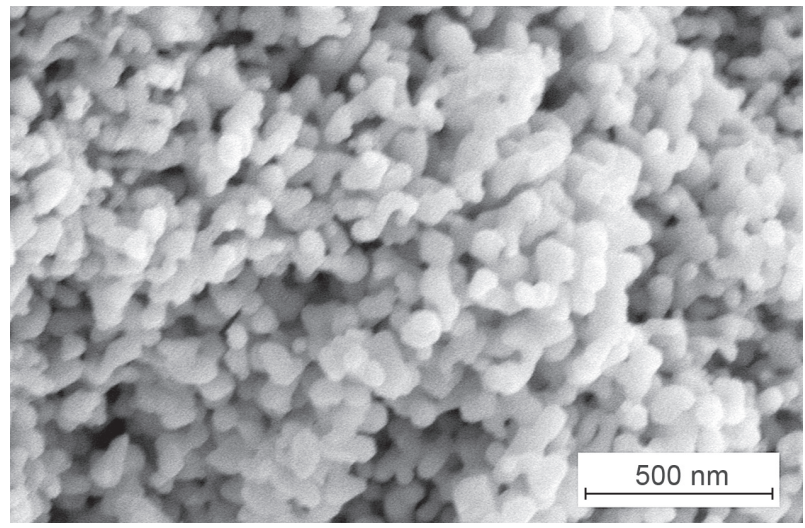

d)

Figure 5. XRD patterns (a) for $\mathrm{ZrC} \mathrm{Hf}_{0.5} \mathrm{Zr}_{0.5} \mathrm{C}, \mathrm{Hf}_{0.9} \mathrm{Zr}_{0.1} \mathrm{C}$, $\mathrm{HfC}$ precursors pyrolysed at $1400^{\circ} \mathrm{C}$ (a), magnified image (b) of the dashed zones in (a), and the corresponding SEM images of: c) $\mathrm{HfC}$, d) $\mathrm{Hf}_{0.5} \mathrm{Zr}_{0.5} \mathrm{C}$ powders. 
agrees well with XRD results and further confirms the existence of zirconium and hafnium ternary carbide products. The existence of $\mathrm{O}$ element is believed to be due to the contamination on the surface of the powders.

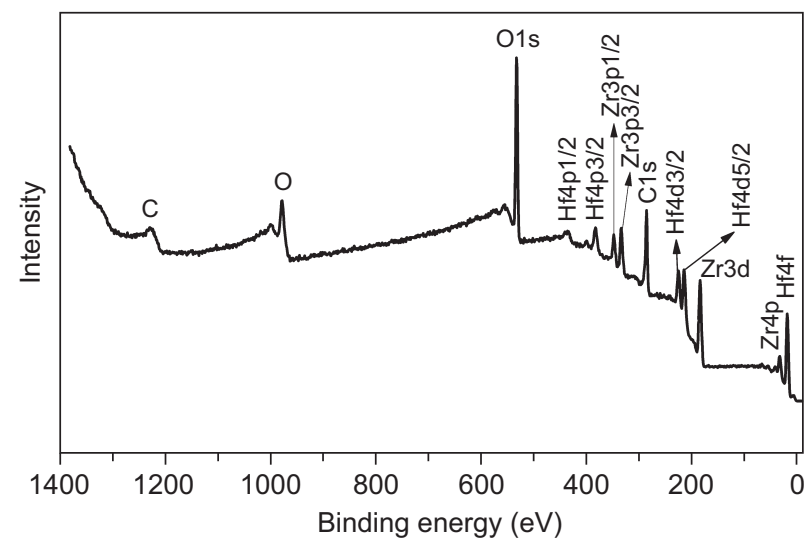

Figure 6. XPS survey scan of $\mathrm{Hf}_{0.5} \mathrm{Zr}_{0.5} \mathrm{C}$ powders obtained at $1400^{\circ} \mathrm{C}$.

Figure 7 shows TEM images of $\mathrm{ZrC}$ and $\mathrm{Hf}_{0.5} \mathrm{Zr}_{0.5} \mathrm{C}$ powders obtained at $1400^{\circ} \mathrm{C}$. Both $\mathrm{ZrC}$ and $\mathrm{Hf}_{0.5} \mathrm{Zr}_{0.5} \mathrm{C}$ powders have a fine particle size and are heavily aggregated. These carbide particles have a narrow dispersity and possess a particle size of $50-100 \mathrm{~nm}$ by TEM technique, which agrees well with the SEM result.

\section{CONCLUSIONS}

Zirconium carbide, hafnium carbide and their ternary carbide powders have been successfully synthesized via an entirely aqueous solution-gel route. In this paper, zirconium oxychloride $\left(\mathrm{ZrOCl}_{2} \cdot 8 \mathrm{H}_{2} \mathrm{O}\right)$, malic acid (MA) and ethylene glycol (EG) were used to prepare the $\mathrm{ZrC}$ precursor. The FT-IR results of the precursor gel showed that malic anion was coordinated to the zirconium ion. The heat treatment of the gel led to the formation of $\mathrm{ZrC}$ without any oxide phase at $1200^{\circ} \mathrm{C}$ due to an intimate mixing of the intermediate products. Furthermore, this aqueous solution-gel route was also used to produce hafnium carbide and the ternary carbide powders, and the ternary carbide powders exhibited a single-phase of NaCl-type. All zirconium carbide, hafnium carbide and ternary carbide powders had a particle size of $\sim 100 \mathrm{~nm}$. The importance of this aqueous solution-gel method to minimizing the amount of toxic chemicals during solution processing is therefore addressed.

\section{Acknowledgments}

This work was financially supported by Aid Program for Science and Technology Innovative Research Team in Higher Educational Institutions of Hunan Province, and Aid Program for Innovative Group of National University of Defense Technology.

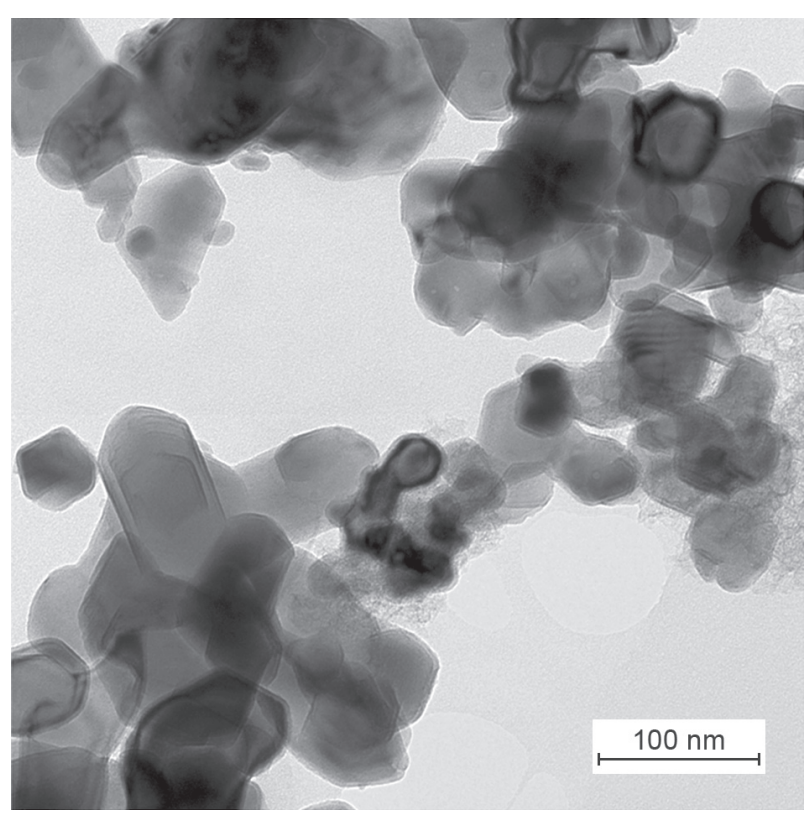

a)

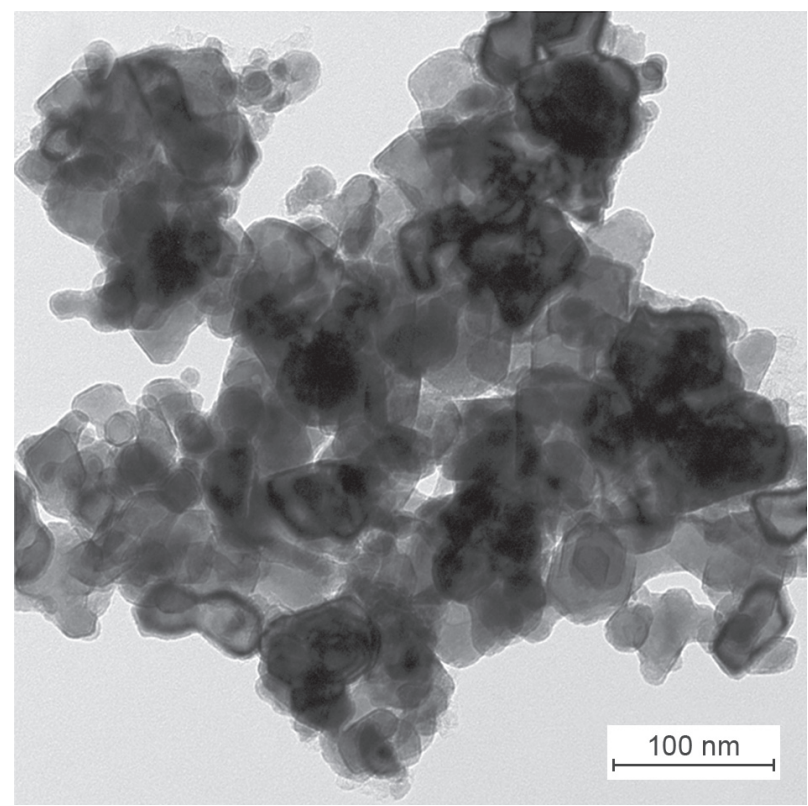

b)

Figure 7. TEM images of: a) $\mathrm{ZrC}$ and b) $\mathrm{Hf}_{0.5} \mathrm{Zr}_{0.5} \mathrm{C}$ powders obtained at $1400^{\circ} \mathrm{C}$.

\section{REFERENCES}

1. Preiss H., Schultze D., Szulzewsky K. (1999): Carbothermal synthesis of vanadium and chromium carbides from solution-derived precursors. Journal of the European Ceramic Society, 19, 187-194. doi:10.1016/S0955-2219 (98)00191-5

2. Yan C.L., Liu R.J., Cao Y.B., Zhang C.R., Zhang D.K. (2014): Preparation and properties of 3D needle-punched $\mathrm{C} / \mathrm{ZrC}-\mathrm{SiC}$ composites by polymer infiltration and pyrolysis process. Ceramics International 40, 10961-10970. doi:10.1016/j.ceramint.2014.03.099 
3. Sonber J.K., Murthy T.S.R.CH., Sairam K., Chakravartty J.K. (2016): Effect of $\mathrm{NdB}_{6}$ addition on densification and properties of $\mathrm{ZrB}_{2}$. Ceram-Silikáty, 60, 41-47. doi: $10.13168 /$ cs.2016.0006

4. Silvestroni L., Sciti D., Kling J., Lauterbach S., Kleebe H.J. (2009): Sintering mechanisms of zirconium and hafnium carbides doped with $\mathrm{MoSi}_{2}$. Journal of the American Ceramic Society, 92, 1574-1579. doi:10.1111/j.1551-2916. 2009.03049.x

5. Paul A., Jayaseelan D.D., Venugopal S., Zapata-Solvas E., Binner J., Vaidhyanathan B., Heaton A., Brown P., Lee W.E. (2012): UHTC composites for hypersonic applications. The American Ceramic Society Bulletin, 91, 22-29.

6. Zhao D., Zhang C.R., Hu H.F., Zhang Y.D. (2011): Preparation and characterization of three-dimensional carbon fiber reinforced zirconium carbide composite by precursor infiltration and pyrolysis process. Ceramics International, 37, 2089-2093. doi:10.1016/j.ceramint.2011.02.024

7. Blum Y.D., Marschall J., Hui D., Adair B., Vestel M. (2008): Hafnium reactivity with boron and carbon sources under non-self-propagating high-temperature synthesis conditions. Journal of the American Ceramic Society, 91, 1481-1488. doi:10.1111/j.1551-2916.2008.02329.x

8. Thorne K., Ting S.J., Chu C.J., Mackenzie J.D., Getman T.D., Hawthorne M.F. (1992): Synthesis of TiC via polymeric titanates: the preparation of fibres and thin films. Journal of Materials Science, 27, 4406-4414. doi:10.1007/ BF00541573

9. Jiang Z.P., Rhine W.E. (1991): Preparation of TiN and TiC from a polymeric precursor. Chemistry of materials, 3, 1132-1137. doi:10.1021/cm00018a033
10.Stanley D.R., Birchall J.D., Hyland J.N.K., Thomas L., Hodgetts K. (1992): Carbothermal synthesis of binary $(\mathrm{MX})$ and ternary $\left(\mathrm{M}^{1}, \mathrm{M}^{2} \mathrm{X}\right)$ carbides, nitrides and borides from polymeric precursors. Journal of Materials Science, 2, 149-156. doi:10.1039/JM9920200149

11. Wu H.T., Zhang W.G., Zhang J.H. (2014): Pyrolysis synthesis and microstructure of zirconium carbide from new preceramic polymers. Ceramics International, 40, 5967-5972. doi:10.1016/j.ceramint.2013.11.044

12.Tao X.Y., Wei X.Y., Chen Q., Lu W.Z., Ma M., Zhao T. (2013): Synthesis, characterisation and thermal behaviour of new preceramic polymers for zirconium carbide. Advances in Applied Ceramics, 112, 301-305. doi:10.1179/1743 676113Y.0000000076

13. Yan C.L., Liu R.J., Cao Y.B., Zhang C.R., Zhang D.K. (2012): Carbothermal synthesis of submicrometer zirconium carbide from polyzirconoxane and phenolic resin by the facile one-pot reaction. Journal of the American Ceramic Society, 95, 3366-3369. doi:10.1111/j.1551-2916. 2012.05456.x

14.Durupthy O., Bill J., Aldinger F. (2007): Bioinspired synthesis of crystalline $\mathrm{TiO}_{2}$ : effect of amino acids on nanoparticles structure and shape. Crystal Growth and Design, 7, 2696-2704. doi:10.1021/cg060405g

15.Kefalas E.T., Panagiotidis P., Raptopoulou C.P., Terzis A., Mavromoustakos T., Salifoglou A. (2005): Mononuclear titanium(IV)-citrate complexes from aqueous solutions: $\mathrm{PH}$-specific synthesis and structural and spectroscopic studies in relevance to aqueous titanium(IV)-citrate speciation. Inorganic chemistry, 44, 2596-2605. doi:10.1021/ ic0492760 